\title{
Influence of oxide additions in Cu-Co-Fe composite powders obtained by mechanical alloying
}

\author{
LLORCA-ISERN Núria ${ }^{1, a}$, ARTIEDA-GUZMAN Cristina ${ }^{1, b}$, VIQUE Jose Alberto ${ }^{1, c}$ and \\ ROCA Antoni ${ }^{1, d}$
}

${ }^{1} \mathrm{CPCM}$, Dept. Ciència dels Materials i Enginyeria Metal-lúrgica, Facultat de Química, Universitat de Barcelona, Marti-Franques 1, 08028 Barcelona, Spain

anullorca@ub.edu, bcristinaartieda@ub.edu, cjviqueal7@alumnes.ub.edu, droca@ub.ed

Keywords: Composite powder, mechanical milling, Cu-Fe-Co, ceramic reinforcement, magnetic properties, catalysts, microelectronics.

\begin{abstract}
Nanocrystalline composite powders were prepared by mechanical alloying of pure $\mathrm{Cu}, \mathrm{Fe}$ and $\mathrm{Co}$ as metallic major part and $\mathrm{Al}_{2} \mathrm{O}_{3}$ or $\mathrm{Fe}_{2} \mathrm{O}_{3}$ or $\mathrm{SiO}_{2}$ as ceramic reinforcement in a highenergy ball mill. Alloys of the copper-iron-cobalt system are promising for the development of new materials and applications. $\mathrm{Cu}-\mathrm{Fe}-\mathrm{Co}$ is used in different applications depending on the properties required. These can be related for example to toughness when used as rock cutting tool, to magnetic and electric properties for microelectronics or to chemical behaviour when used as catalysts in bioalcohol production industry. The objective of the present study is to contribute to understanding how and to which amount the ceramic reinforcement affects the properties for which this $\mathrm{Cu}-\mathrm{Fe}-\mathrm{Co}$ system is used as well as to envisage other less frequently uses for the composite powders. Structural and magnetic transformations occurring in the material during milling were studied with the use of X-ray diffraction, scanning quantum induction device (SQUID) and magnetic force microscopy (MFM). In mechanical alloying the transformations depend upon milling time. The results showed that milling the elemental powders of $\mathrm{Cu}-\mathrm{Fe}-\mathrm{Co}$ in the mass proportion of 50:25:25 respectively for times up to $10 \mathrm{~h}$ leads to the progressive dissolution of $\mathrm{Fe}$ and $\mathrm{Co}$ atoms into $\mathrm{FCC}$ $\mathrm{Cu}$ and the final product of the MA process was the nanocrystalline $\mathrm{Cu}$ containing $\mathrm{Fe}$ and $\mathrm{Co}$ with a mean crystallite size (from coherent crystal size determination by diffraction) of $20 \mathrm{~nm}$ aprox. When ceramic particles are milled together with the metals (at proportions of the oxides between 1$10 \%$ ) this mechanism is retarded. On the other hand, the lowest mean crystallite size is reached without ceramic particles in the milling process. However the composite powder produced in all the cases stabilized similar lowest crystallite size between $45-50 \mathrm{~nm}$. Mechanically alloyed metallicceramic composite powder showed lower saturation magnetization than the metallic system but enhanced coercive field (significantly for hematite reinforcement). All the studied systems are intermediate ferromagnetics $\left(\mathrm{H}_{\mathrm{c}} \approx 104 \mathrm{~A} / \mathrm{m}\right)$. Milling time significantly affects the structure, composition and properties for both metallic and composite systems.
\end{abstract}

\section{Introduction}

Mechanical alloying is a well-known powerful method for the synthesis of nanocrystalline powders [1-3]. It involves repeated fracturing and rewelding of particles, leading to size reduction and particle shape changes. In addition, mechanical alloying techniques (MA) are widely used for the production of soft magnetic alloys.

Copper and copper alloys are one of the major groups of commercial materials used in engineering, due to their excellent properties, although for some applications these materials need to be strengthened by alloying or by introducing different insoluble elements or compounds to achieve particle strengthening and form a metal composite material (MCM). $\mathrm{Cu}-\mathrm{Fe}-\mathrm{Co}$ alloys have useful magnetic properties; this is the reason for their potential to be used in very different fields such as microelectronic parts and circuit systems or applications that make use of their giant magnetoresistance effect (GMR) [4]. The limited solubility of iron and cobalt in copper allows the matrix to retain high conductivity. As a result, this composite may be useful in applications in which high conductivity and high strength are required [5]. Another field in which this metallic 
combination is used is for adsorption, activation and conversion of $\mathrm{CO}_{2}$ to $\mathrm{CO}$. These processes carried out on transition metal ( $\mathrm{Fe}, \mathrm{Co}, \mathrm{Ni}$ and $\mathrm{Fe}$ ) surface catalysts supported by $\mathrm{Al}_{2} \mathrm{O}_{3}, \mathrm{SiO}_{2}$ and others have been of interest for many years. A strong correlation was discovered between intrinsic activity of heterogeneous and homogeneous $\mathrm{CO}_{2}$ catalysis as a function of $3 \mathrm{~d}$ metal [6]. On the other hand, there is wide agreement that mass production of fuel cells for transportation and domestic uses will lead to scarcity and cost-increase of Pt-based catalysts. It is, therefore, reasonable to research focused on Pt replacement by more abundant transition metals such as $\mathrm{Fe}$, $\mathrm{Co}, \mathrm{Cu}, \mathrm{Mn}, \mathrm{Mo}$ for multielectron transfer catalysis [7]. In the case of oxygen reduction it is well known that using a Fe-Cu center the catalytic problem is solved in nature [8].

One of the production methods for these alloys starts with the powder of the three metals, as the binary systems $\mathrm{Fe}-\mathrm{Cu}$ and $\mathrm{Co}-\mathrm{Cu}$ show immiscibility a metastable solid solution of the ternary $\mathrm{Cu}-$ $\mathrm{Fe}-\mathrm{Co}$ can be produced by mechanical alloying. The metallic combination may need different ceramic support depending on the application for this reason the elementary metals are milled together with the ceramic in order to study the final composite powder behaviour. Magnetic properties depend on crystallite size, lattice strain and element shape. All of these factors determine the hysteresis loop and consequently affect magnetic parameters such as saturation magnetization, Ms, coercivity, Hc, and remanence, Mr. Magnetic force microscopy (MFM) has become one of the most widespread tools for studying the magnetic domains of ferromagnetic samples [9]. Some authors [10-12] report MFM investigations of ribbons of melt-spun nanomaterials and electrodeposited layers and films, but the use of MFM in the study of mechanical alloyed nanopowders has not been widely reported yet [9].

The present study is focused on the effect of alumina, hematite and silica additions to $\mathrm{Cu}-\mathrm{Fe}-\mathrm{Co}$ at different percentages of the ceramic material to evaluate how the microstructure, the coherent diffraction domains size and the magnetic properties are affected. The microstructure, magnetic properties and magnetic domains variation of all samples were investigated by X-ray diffraction (XRD), SQUID Magnetometer and Magnetic Force Microscopy, respectively.

\section{Material and methods}

Element powders of $\mathrm{Cu}, \mathrm{Fe}$ and $\mathrm{Co}$ (mass ratio 50:25:25) were used as the starting materials, with particle size of 15-20 $\mu \mathrm{m}, 4-6 \mu \mathrm{m}$, and 1-2 $\mu \mathrm{m}$, respectively. The ceramic material selected to be added in 1, 3 and $10 \mathrm{wt} \%$ to the metallic system was $\alpha-\mathrm{Al}_{2} \mathrm{O}_{3}, \alpha-\mathrm{Fe}_{2} \mathrm{O}_{3}$ or $\mathrm{SiO}_{2}$ ( $\alpha$-quartz) with a particle size of around $1 \mu \mathrm{m}$. Four sets of samples with the same compositional ratio were processed by high-energy ball milling in a Fritsch planetary monomill Pulverisette P6 with steel balls and vials. This equipment works at the specific impact energy of the balls of $6-7 \mathrm{~kJ} / \mathrm{s}^{-1} \mathrm{~kg}^{-1}$ [9]. The experimental conditions of the mechanical alloying process (MA) were the following: disc rotation speed of $300 \mathrm{rpm}(\Omega)$ and vial rotation speed of $546 \mathrm{rpm}(\omega)$ and the ball-to-powder weight ratio was 16:1 in all experiments. The process was performed under Ar atmosphere to prevent oxidation.

Characterization techniques. The microstructural characterization of samples was carried out by X-Ray powder diffraction (XRD) performed in the classical Bragg-Brentano PANalytical X'Pert $P R O M P D \theta / \theta$ geometry, on a wide angle diffractometer, using $\mathrm{Cu} \mathrm{K} \alpha$ radiation $(\lambda=1.5418 \AA)$. Scans were collected in small angular steps of $2 \theta=0.017^{\circ}$. The phases formed during processing were identified by X'Pert HighScore Plus software. FullProf_Suite standard software was used as a graphic tool to carry out the diffraction profile fitting peak-to-peak to obtain the full width at halfmaximum (FWHM) of each sample. The adjustment was performed using the pseudo-Voigt function. The XRD microstructural analysis was based on the fact that the diffraction profiles of a polycrystalline solid have a shape determined by the imperfections of the material, among other factors. Since the mechanical alloying process causes severe plastic deformation which introduces many defects and stresses in the alloyed system, in this type of samples, the main factors that contribute to broadening are the instrumental broadening profile and the intrinsic broadening profile (included crystallite size and microstrain). In this study, the deconvolution hypotheses in all the 
samples were analysed to determine which was best for representing the intrinsic broadening. The crystallite size (D) and microstrain determination were carried out using the copper diffraction peaks (as iron and cobalt atoms rapidly diffused within the lattice of $\mathrm{Cu}$ and disappeared as diffraction peaks during MA).

In all the samples, the variation of magnetic parameters with processing time and ceramic additions, was measured at $5 \mathrm{~K}$ and $300 \mathrm{~K}$ for some compositions in a maximum field of $50 \mathrm{kOe}$ using a SQUID MPMS-XL superconducting quantum interference device from Quantum Design. The magnetic domain structure was imaged using magnetic force microscopy (MFM) (AFM Dimension 3100, Veeco).

\section{Results and Discussion}

Microstructural transformations associated with mechanical alloying. The structural evolution and phase formation of the as-milled powders was examined by microscopy and also by recording the X-ray diffraction (XRD) patterns as a function of milling time and ceramic additions. As an example, Fig. 1 shows the different morphology of the powder, Cu50Fe25Co25 and $\mathrm{Cu} 50 \mathrm{Fe} 25 \mathrm{Co} 25+3 \% \quad \mathrm{Al}_{2} \mathrm{O}_{3}$ (in mass), after 10h milling: ductile-ductile mechanism and ductilebrittle mechanism respectively.
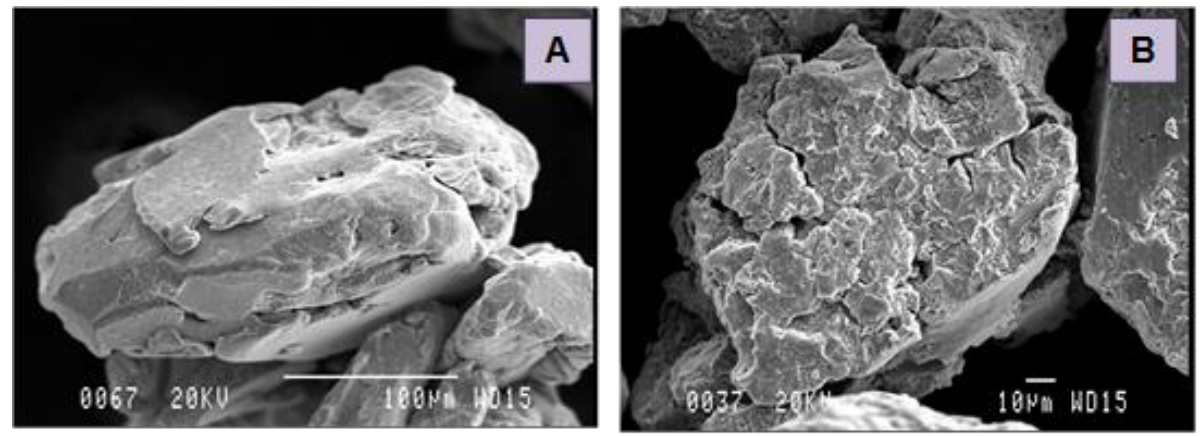

Figure 1. SEM micrographs of powder after 10h milling, (a) metallic system, (b) composite powder (metals $+3 \%$ alumina).

Ball milling influences the microstructure of the systems with which it interacts. In the present study it promotes the mechanical alloying of the elementary metals. During milling cobalt first and iron after enter into the copper until they progressively lower their value as elementary metals. Deconvolution of X-ray diffraction peaks is necessary in order to interpret the microstructural changes that can be reached during the milling process. From this, the final formation of some Co$\mathrm{Fe}$ inside the $\mathrm{Cu}$ is suggested.

The evaluation of the XRD patterns as a function of milling time let us conclude that the addition of ceramic hindered the metallic alloying. This effect is directly related to the amount of oxides added, for instance lower addition does not influences the process but $3 \%$ and $10 \%$ significantly controlled the mechanical alloying process. As can be seen in Fig. 2, at the same time of milling composite powders evidence the presence of elementary Fe whereas metallic powder needs deconvolution for a more precise identification.

Fig. 3 shows the deconvolution of the diffraction peaks at $2 \theta=41.6-45.2^{\circ}$ for metallic (milled for $3 \mathrm{~h}$ and $10 \mathrm{~h}$ ) and composite $\mathrm{CuFeCo}-10 \% \mathrm{Al}_{2} \mathrm{O}_{3}$ powders MA for 10h. Four functions with centre angles of $43.17,43.46,44.05$ and 44.50 respectively, are required to describe the two large peaks of metallic powder milled for $3 \mathrm{~h}$ while only one peak is needed for longer processing time. Deconvolution suggests that at $3 \mathrm{~h}$ powder contains $\mathrm{Cu}, \mathrm{Co}, \mathrm{Fe}$ and a new phase in which $\mathrm{Cu}$ solubilizes $\mathrm{Co}$ and $\mathrm{Fe}$; at $8 \mathrm{~h}$ milling this latter phase is majoritary and only small amounts of elementary $\mathrm{Co}$ and $\mathrm{Fe}$ remain; beyond $10 \mathrm{~h}$ of processing time, deconvolution fits the large peak for $\mathrm{Cu}(\mathrm{Co}, \mathrm{Fe})$ together with remnant $\mathrm{Fe}$ as small broadened peak. The presence of small amounts of $\mathrm{Fe}$ 
was also found and detected with Mossbauer analyses by Laslouni et al [13] even for longer processing time.

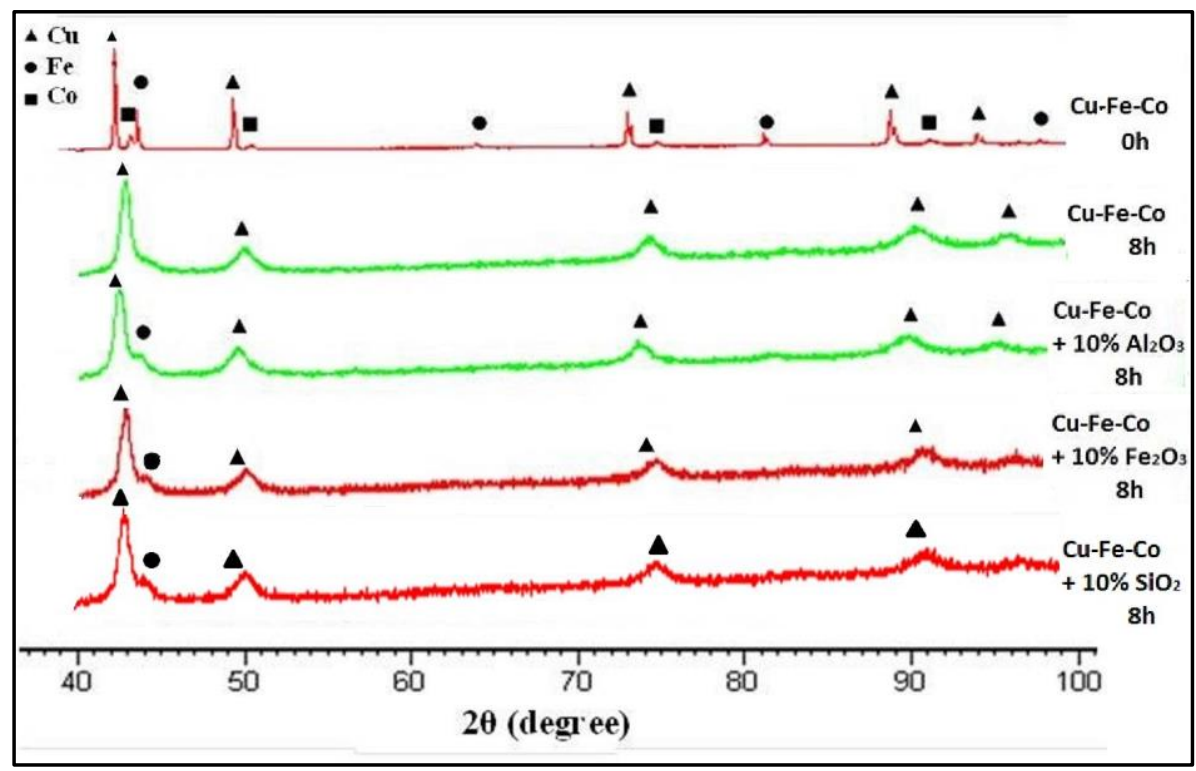

Figure 2. Comparison of X-ray diffraction patterns of mechanically alloyed $\mathrm{Cu}-\mathrm{Fe}-\mathrm{Co}$ composite powders. From top to bottom: $\mathrm{Cu}-\mathrm{Fe}-\mathrm{Co}$ metallic powder (unmilled), $\mathrm{Cu}-\mathrm{Fe}-\mathrm{Co} 8 \mathrm{~h}$ milling, $\mathrm{CuFeCo}+10 \% \quad \mathrm{Al}_{2} \mathrm{O}_{3}$ composite powder $8 \mathrm{~h}$ milling, $\mathrm{CuFeCo}+10 \% \quad \mathrm{Fe}_{2} \mathrm{O}_{3}$ composite powder $8 \mathrm{~h}$ milling and $\mathrm{CuFeCo}+10 \% \mathrm{SiO}_{2}$ composite powder $8 \mathrm{~h}$ milling.
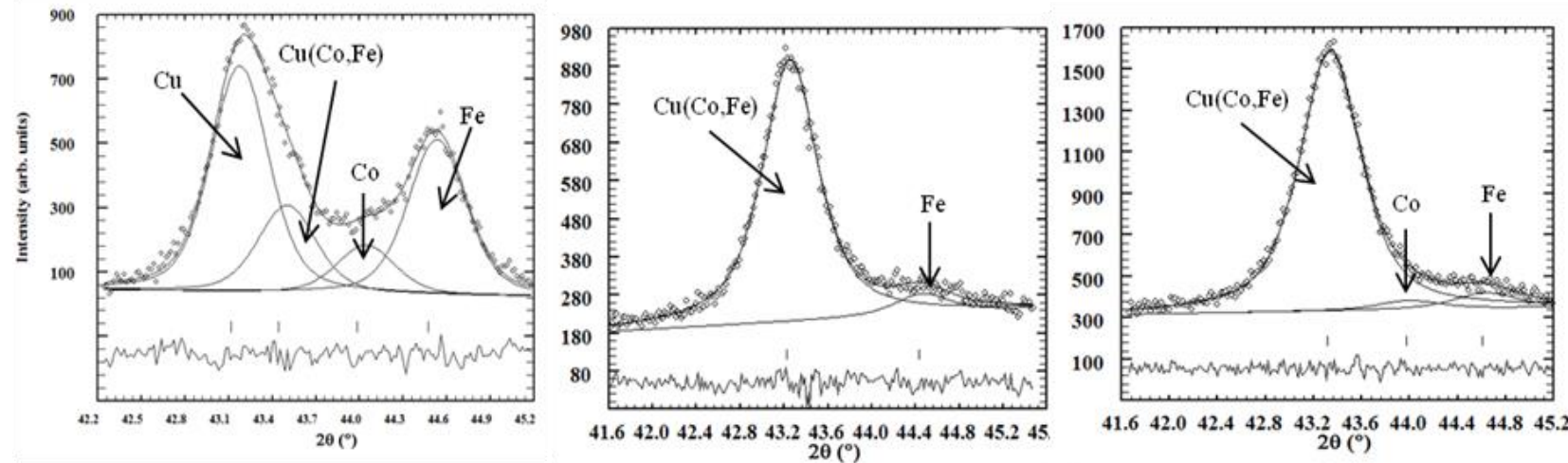

Figure 3. Observed (points) and deconvoluted (solid line) X-ray diffraction pattern of (111) peak for $3 \mathrm{~h}$ (left) and $10 \mathrm{~h}$ (center) of metallic powder and $10 \mathrm{~h}$ of $10 \% \mathrm{Al}_{2} \mathrm{O}_{3}$ composite powder (right). Positions of the Bragg reflections are represented by vertical bars. The observed-calculated difference pattern is depicted at the bottom of each figure. (For metallic powder milled $3 \mathrm{~h}$ sample: $\mathrm{R}_{\mathrm{p}}=4.6 \% ; \mathrm{R}_{\mathrm{wp}}=7.7 \%$; $\mathrm{R}_{\mathrm{exp}}=5.3 \%$; for metallic powder milled $10 \mathrm{~h}$ sample: $\mathrm{R}_{\mathrm{p}}=3.6 \% ; \mathrm{R}_{\mathrm{wp}}=4.5 \%$; $\mathrm{R}_{\mathrm{exp}}=5.1 \%$; for composite powder milled $10 \mathrm{~h}$ sample: $\mathrm{R}_{\mathrm{p}}=2.7 \% ; \mathrm{R}_{\mathrm{wp}}=3.6 \%$; $\mathrm{R}_{\mathrm{exp}}=3.9 \%$ ).

At $10 \mathrm{~h}$ of processing time, deconvolution fits the large peak for $\mathrm{Cu}(\mathrm{Co}, \mathrm{Fe})$ together with remnant $\mathrm{Co}$ and $\mathrm{Fe}$ as small broadened peaks. Peak function centre angle of $2 \theta=43.32^{\circ}$ and $43.31^{\circ}$ is considered to belong to $\mathrm{Cu}(\mathrm{Co}, \mathrm{Fe})$ phase. As can be seen when $\mathrm{Al}_{2} \mathrm{O}_{3}$ is present the diffusion of $\mathrm{Fe}$ and $\mathrm{Co}$ is detected at longer milling time, between $8 \mathrm{~h}$ and $10 \mathrm{~h}$. This can be explained by the fact that alumina acts as to block the diffusion of iron atoms. Hence if ceramic particles are introduced in the MA process mass transfer is hindered and the kinetics to produce any kind of solid solution wane as it is found experimentally in the present study.

The crystal size (D) of all samples was obtained and was dependent on the milling time: two distinct behaviours can be determined: one followed by the metallic powders and another shown by all the composite powders. The evolution of the crystallite size of the metallic series monotonically decreases with increasing milling time, in contrast to all the composite series. At 3 hours milling the 
crystallite size for metallic and composite powders was around $80 \mathrm{~nm}$ and $50 \mathrm{~nm}$, respectively. This disagreement may be due to the addition of the hard and brittle ceramic materials to the metallic system, which causes a fracture mechanism to become dominant and induces a rapid decrease of D. In contrast, in the metallic system there was a more equitable balance between welding and fracture, which produced a more gradual decrease in crystal size. At ten hours of processing, all the samples had a very similar crystal size of approximately $40 \mathrm{~nm}$. Therefore, this was a critical point and coincided with the time required to produce the possible solid solutions of $\mathrm{Cu}(\mathrm{Fe}, \mathrm{Co})$. After $10 \mathrm{~h}$ milling, the metallic system acquired a stationary value of crystal size. In contrast, the rest of the compositional series had an increase in D. There was no significant difference in crystal size variation between the three composite series, showing that a rise in the percentage of ceramic in the metallic system promotes a slight decrease in $\mathrm{D}$ as the brittleness of the system is increased.

Magnetic measurements and MFM images showed that the plastic deformation introduced by mechanical alloying leads to a microstrained structure affecting the total energy of the magnetized samples. All samples showed ferromagnetic behaviour as all of them produced hysteresis loops and saturated when a magnetic field of $50 \mathrm{KOe}$ was applied (Fig. 4). Coercivity was dependent on the crystallite size for all the compositional series under study $(\mathrm{Hc} \approx 104 \mathrm{~A} / \mathrm{m})$. The complex magnetic patterns of the composite powders made difficult the magnetic force microscopy particularly alumina and silica additions for which the system does not show clear specific morphology of the magnetic domains and poor magnetic contrast compared to the metallic system.
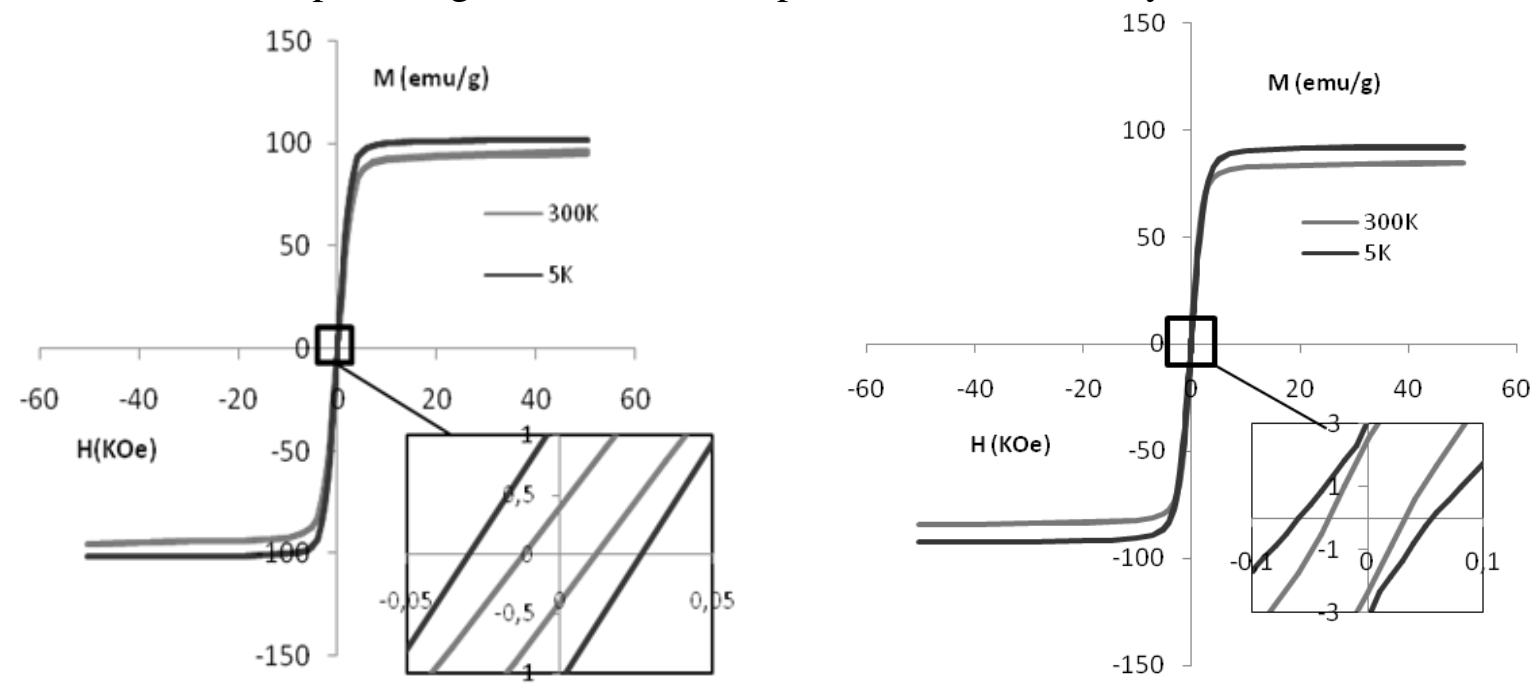

Figure 4. Hysteresis loop at $5 \mathrm{~K}$ and $300 \mathrm{~K}$ for the metallic powder (left) and composite sample with $10 \%$ of alumina (right) milled for 16 hours.

Finally, the sintering ability of each system was also studied. The present results showed that the alumina and silica particles were rather difficult for sintering the composite whereas hematite was suitable for sintering at temperatures below $550^{\circ} \mathrm{C}$.

\section{Summary}

The addition of ceramic particles $\left(\alpha-\mathrm{Al}_{2} \mathrm{O}_{3}, \alpha-\mathrm{Fe}_{2} \mathrm{O}_{3}\right.$ or $\left.\mathrm{SiO}_{2}\right)$ in the $\mathrm{Cu}-\mathrm{Fe}-\mathrm{Co}$ metallic powder tends to decrease the crystal size measured by XRD down to $45-50 \mathrm{~nm}$ for the same milling time whereas in the absence of oxides, the crystal size reached $20-25 \mathrm{~nm}$ at the same milling time.

When the milling time was increased, the saturation magnetization became higher but the coercivity decreased. Consequently, as the processing time increased the material became more soft ferromagnetic. When ceramic particles are added to the $\mathrm{Cu}-\mathrm{Fe}-\mathrm{Co}$ system, the magnetic domains did not show specific morphology as the particles seemed to act as the anchor of magnetic domains and possibly also distorted and prevented them from being uniformly distributed.

Composite hematite powder sintering produces almost fully densified samples. 


\section{Acknowledgments}

The authors wish to thank Ms. Esther Vilalta as well as the CCCiT (University of Barcelona) for their collaboration.

\section{References}

[1] R. Koohkan, S. Sharafi, H. Shokrollahi, K. Janghorban, Preparation of nanocrystalline Fe-Ni powders by mechanical alloying used in soft magnetic composites, J. Magn. Magn. Mater. 320 (2008) 1089-1094.

[2] R. Hamzaoui, O. Elkedim, N. Fenineche, E. Gaffet, J. Craven, Structure and magnetic properties of nanocrystalline mechanically alloyed Fe-10\% Ni and Fe-20\%Ni, Mat. Sci. Eng. 360 (2003) 299305.

[3] B. Bhoi, V. Srinivas, Vidyadhar Singh, Evolution of microestructure and magnetic properties of nanocrystalline Fe70-xCuxCo30 alloy prepared by mechanical alloying, J. Alloys Compd. 496 (2010) 423-428.

[4] R. Lardé, J.M. Le Breton, X. Sauvage, Investigation of the chemical homogeneity of $\mathrm{Cu} 80(\mathrm{Fe}, \mathrm{Co}) 20$ powders produced by mechanical milling, J. Alloys Compd. 474 (2009) 52-56.

[5] M. Azabou, H.Ibn Gharsallah, L.Escoda, J.J. Suñol, A.W. Kolsi, M. Khitouni, Mechanochemical reactions in nanocrystalline $\mathrm{Cu}-\mathrm{Fe}$ system induced by mechanical alloying in air atmosphere, Powder Metall. 224 (2012) 338-344.

[6] C. Liu, T.R. Cundari, A.K. Wilson, CO2 Reduction on Transition Metal (Fe, Co, Ni, and Cu) Surfaces: In Comparison with Homogeneous Catalysis, The journal of Physical Chemistry C, 116 (2012) 5681-5688.

[7] B. Wang, Recent development of non-platinum catalysts for oxygen reduction reaction, J. Power Sources 152 (2005) 1.

[8] H. Tributsch, U. I. Koslowski, I. Dorbandt, Experimental and theoretical modeling of Fe-, Co-, $\mathrm{Cu}-, \mathrm{Mn}$-based electrocatalysts for oxygen reduction, Electrochemica Acta, 53 (2008) 2198-2209.

[9] C. Artieda-Guzman, N. Llorca-Isern, Magnetic behaviour of nanocrystalline $\mathrm{Cu}-\mathrm{Fe}-\mathrm{Co} / \mathrm{Al} 2 \mathrm{O} 3$ composite powders obtained by mechanical alloying, J. Alloys Compd.580 (2013) 276-283.

[10] O. Öztürk, S. Okur, L. Pichon, M.O. Liedke, J.P. Riviere, Magnetic layer formation on plasma nitrided CoCrMo alloy, Surf. Coat. Tech. 205 (2011) 280-285.

[11] G.F. Korznikova, Domain structures of ultrafine grained ferromagnets achieved by severe plastic deformation or melt quenching, J. Microsc. 239 (2010) 239-244.

[12] D. Płusa, M. Dospiał, D. Derewnicka-Krawczynska, P. Wieczorek, U. Kotlarczyk, The domain structure of die-upset anisotropic magnet based on Nd-(Fe, Co)-B alloy, Arch. Metall. Mater. 56 (2011) 159-161.

[13] W. Laslouni, K. Taibi, D. Dahmoun, M. Azzaz, Structure and properties of nanocrystalline $\mathrm{Cu}_{70} \mathrm{Fe}_{18} \mathrm{Co}_{12}$ obtained by mechanical alloying, J. Non Cry.Sol. 353 (2007) 2090-2093. 